\title{
Key Challenges and Potential Urban Modelling Opportunities in South Africa, with Specific Reference to the Gauteng City-Region
}

\author{
Chris Wray ${ }^{1}$ and Koech Cheruiyot ${ }^{2}$ \\ ${ }^{1}$ Gauteng City-Region Observatory (GCRO), a partnership between the University of \\ Johannesburg, the University of the Witwatersrand, Johannesburg, the Gauteng Provincial \\ Government and organised local government. Private Bag 3, Wits 2050, South Africa. \\ Email: chris.wray@gcro.ac.za \\ ${ }^{2}$ Gauteng City-Region Observatory (GCRO), a partnership between the University of \\ Johannesburg, the University of the Witwatersrand, Johannesburg, the Gauteng Provincial \\ Government and organised local government. Private Bag 3, Wits 2050, South Africa.
}

\section{DOI: http://dx.doi.org/10.4314/sajg.v4i1.2}

\begin{abstract}
Urban growth and land use change models, supported by Geographic Information Systems (GIS) software and increased digital data availability, have the potential to become important tools for monitoring and guiding urban spatial planning and development. Five broad categories of urban models are utilised internationally, that is, land use transportation models, cellular automata, system dynamics, agent-based models and spatial economics/econometric models. This paper provides a broad overview of South African modelling projects that monitor or simulate urban spatial change. The review identified a variety of government and academic urban modelling initiatives. These initiatives mostly track trends, rather than simulating future scenarios, and analyse historical land cover change using GIS and remote sensing software. There is a risk within Gauteng, however, that out-dated data, different population projections, duplicated tools, limited spatial data infrastructure (SDI) and a lack of resources; could compromise urban spatial change modelling efforts within government institutions. As such, the paper discusses key challenges and opportunities for modelling urban spatial change, with specific reference to the Gauteng CityRegion - the heartland of the South African economy and the Southern African region.
\end{abstract}

\section{Introduction}

In a world described as moving into the urban age, urban areas are not only becoming the dominant form of habitat for humankind, but also the engine-rooms of human development as a whole (UNCHS, 2012). The associated rapid urbanisation raises various challenges, including the expansion of slum settlements, a growing backlog in infrastructure investments, and pressure on available resources such as water, energy and food. Planners and policy makers are required to plan and guide urban development that is socially, economically and ecologically sustainable in an ever more complex and unpredictable context. The importance of developing urban modelling tools to be used by urban professionals to formulate timely and effective policies cannot be overemphasized.

Urban land use modelling involves testing theories regarding spatial location and interactions between different land uses, actors, and other related activities in urban settings (Batty, 2009). 
Importantly, due to advances in computer hardware and software, including Geographic Information Systems (GIS), increased digital data availability, and human understanding of natural and social system functions, urban modelling has evolved from simple calculations of the linear relationships between one or two spatial elements to much more sophisticated simulations of entire urban systems.

South Africa has a plethora of urban modelling initiatives or tools at varying levels of sophistication. Specifically, within the Gauteng City-Region (GCR), there is an ever-growing interest amongst academics and spheres of government to develop tools that will be useful in monitoring and guiding urban spatial change within the city-region. The GCR, with the Gauteng province at its core, is an integrated cluster of cities, towns and urban nodes that together form the economic heartland of South Africa (see Figure 1). Gauteng has experienced rapid urbanisation rates over the past two decades, with an increase in the percentage of urban land cover from $12.6 \%$ in 1991 to $18.35 \%$ in 2009 (Mubiwa and Annegarn, 2013). If the current development trends and in-migration continue, it is estimated that Gauteng's share of the national population will rise to $26.5 \%$ by 2020 (GCRO, 2012).

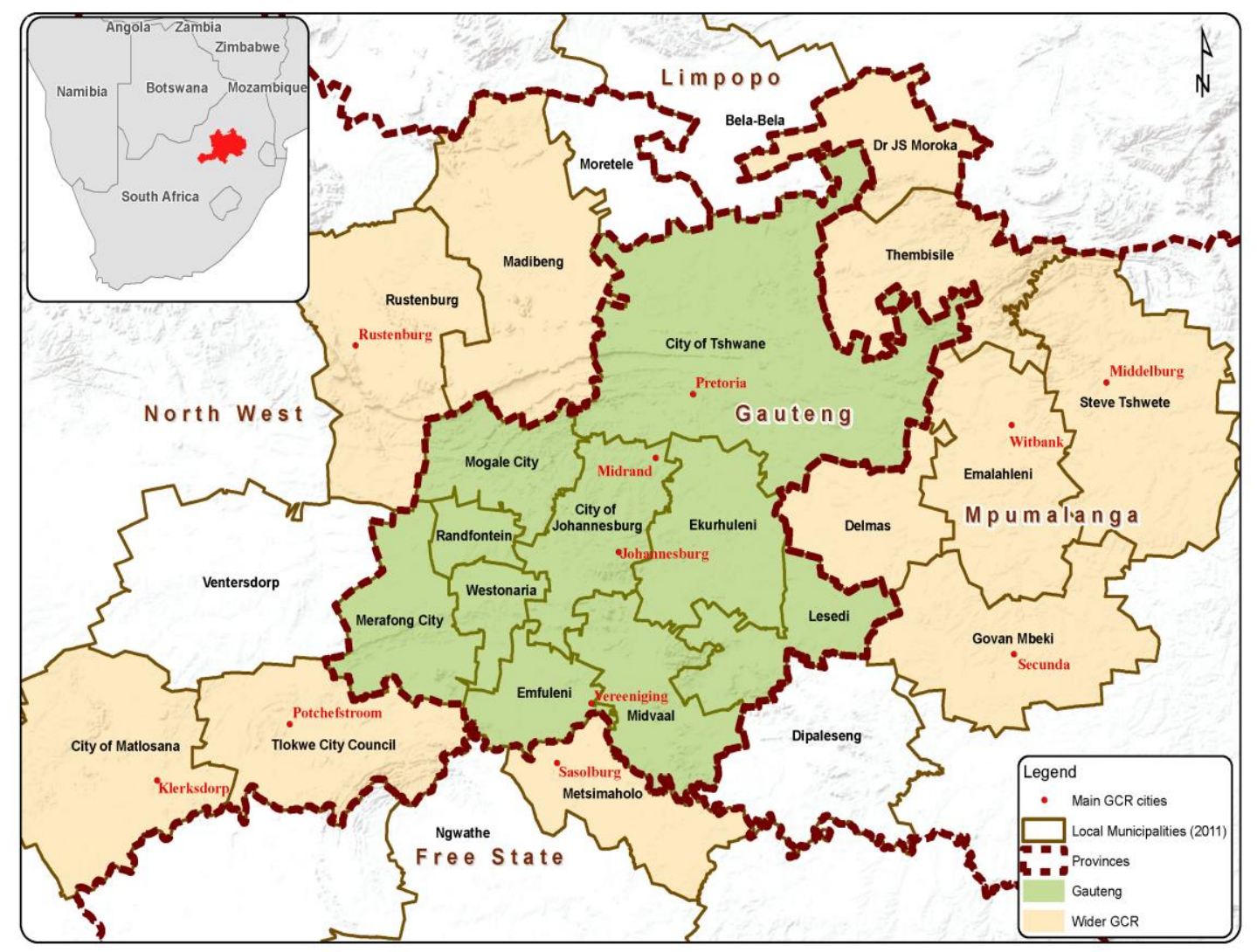

Figure 1. The Gauteng City-Region

Gauteng is anchored by the three large metropolitan municipalities of Johannesburg, Tshwane and Ekurhuleni. However, the wider GCR's economic footprint extends beyond the borders of Gauteng into the neighbouring provinces of Free State, Mpumalanga and North West. The region is 
the largest urban economy in South Africa and Africa as a whole - the Gauteng province alone contributes $34 \%$ of national gross value added (GVA), while the wider GCR accounts for $42 \%$ (GCRO, 2011). The drastic urbanisation and economic growth that the GCR has experienced, which show no signs of abating, demands a critical understanding of the prevailing changing patterns and forces driving urban development.

The Gauteng Planning Commission (GPC) is tasked with long-term integrated city-region planning and the monitoring and evaluation of the provincial government's performance. The GPC's flagship project is the Gauteng 2055 (or G2055) project - a long-term plan that sets out to 'maximise the city-region's potential and its value as a key economic driver for the country, through careful long-term planning aligned with the national vision and other strategic perspectives' (GPC, 2012 , 2). Such long-range development planning processes call for the need to understand more accurately the long-term prospects for urban change and the likely impact of different planning and infrastructure choices and investments on the future urban form through urban spatial change modelling.

Accordingly, this paper had the following objectives: (i) to investigate what aspects or components of urban spatial change are being modelled within South Africa; and (ii) identify key challenges and opportunities for urban modelling in the GCR. To achieve these objectives, the paper specifically addressed the following questions: (i) what aspects or components of urban spatial change are being modelled?; (ii) what urban models were used?; (iii) what data and software are utilised for the various modelling projects?; and (iv) what modelling methodology, software and visualisation tools might be appropriate for an urban change modelling project in the GCR?

A mixed approach was utilised to gather information, with the focus limited to reviewing models that relate to urban spatial and land use growth and change. Firstly, a literature review of urban spatial change modelling and simulation was undertaken. Secondly, a questionnaire was developed and sent to 19 provincial and municipal government departments, government-funded institutions, as well as academic departments involved with urban modelling initiatives in South Africa. Follow up interviews were also held with the relevant personnel involved in the modelling projects in these institutions. South African urban modelling projects were categorised into government (provincial, local and government-funded) and academic initiatives.

The paper is structured as follows. After the introduction, section two explores the meaning of urban modelling and briefly reviews the main types of urban models utilised internationally to contextualise South African modelling initiatives. Section three discusses South African urban modelling initiatives, while section four discusses key modelling challenges and possible modelling opportunities that may benefit and inform long-range development planning processes in the GCR.

\section{Understanding Urban Modelling}

According to Giere (2004) models are generally considered as simple representations of reality or aspects of the world. Batty (2009) adds that models are theoretical abstractions representing systems in such a way that essential features crucial to the theory and its application are identified 
and highlighted. Taking on different forms, such as maps or mental models, various 'tools' in the form of computer programmes or software are utilised to produce them. Useful computer programmes or software include Excel spread sheets, GIS and simulation software. The process of using these tools, given an appropriate theoretical foundation, to simulate urban spatial change or growth is referred to as urban modelling. Urban models are, therefore, mainly computer-based simulations that are utilised to test theories regarding spatial location and the interaction between land uses and other related activities (Batty, 2009).

A review of international literature revealed five broad categories of urban models, that is, land use transportation models (LUT), cellular automata, system dynamics, agent-based models (ABMs), and spatial economics/econometric models (SE/EMs). The review also revealed that instances occur where the existing models are integrated, for example, UrbanSim integrates LUT and ABMs (see, for example, Batty, 2008 \& 2009; Haase and Schwarz, 2009; Berling-Wolff and Wu, 2004; Wegener, 2004).

LUT models, developed and improved over the last four decades, view urban structures as reciprocal relationships between land use and transport (Chang, 2006; Iacono et al., 2008). Drawing their theoretical foundations mainly from regional economics, location theory and new urban economics, LUT models are premised on the fact that there is a symbiotic relationship between transport-planning decisions and the subsequent effect on land use development. For example, a new transport network link may result in an increased investment in land and subsequent land use changes; or if a land use is rezoned this in turn may influence demand for travel. LUT models are, thus, used to explain and predict land use and transport relationships in urban systems treated earlier as static, but now considered dynamic (Batty, 2009). Currently, LUT models incorporate transportation modelling processes of trip generation, distribution, modal split and assignment explicitly and are consistent with discrete choice methods based on utility maximising, specifically in their simulation of trip-making (Akiva and Lerman, 1985). By relying on random utility or discrete choice theory, LUT models try to explain and forecast the behaviour of actors, such as investors, households, firms, or travellers. In this way, individual actors' activities are observed as they maximise a utility, subject to constraints on their choices which can be tailored to reflect how decisions are made in complicated situations (Wegener 2004; Batty 2009).

More recently, a new generation of micro-simulation models (such as UrbanSim) that attempt to account for the behaviour and interactions of individual agents in space and time, have been developed (Iacono et al., 2008). UrbanSim has been applied to a number of cities across the USA, including Detroit, Honolulu, Houston, Phoenix, Salt Lake City, San Francisco, and Seattle. Outside the USA, UrbanSim has been utilised in Accra, Amsterdam, Beijing, Brussels, Paris, Rome, Seoul, Taipei, Tel Aviv, Turin and Zurich (Waddell, 2011).

System dynamics models were introduced in the 1960s through the work of Forrester (1969). In earlier forms, the models were mainly static and based on theories that assumed that systems converge towards stable equilibrium (Berling-Wolff and $\mathrm{Wu}, 2004$ ). This has given way to system models in the present form that treat urban systems as complex, dynamic, and self-organising entities. Treating processes as temporal, dynamic system models appreciate the complex 
interactions that exist within urban systems, such as transport networks, housing, water and energy supply networks. Specifically, dynamic models differ from static models in their three main characteristics, namely: 'spatial structure and relationships among system elements, interactions among the spatial elements, and changes or alterations in the structure and function over time' (Ahmad and Simonovic, 2004, 331). It is worth noting that it was, however, not until the 1970s that dynamic models began to feature in urban-related studies. More recently, various studies are now integrating system dynamics with more explicit spatial approaches (such as GIS and cellular automata) in order to improve the representation of both temporal and spatial processes inherent in urban systems.

International examples of urban-related dynamic models include land use transportation systems for Montgomery County, Maryland (Haghani et al., 2003), Dalian, China (Wang et al., 2008) and as applied within Europe and Asia (Pfaffenbichler et al., 2008). Others have been utilised to plan for airport zones, for example, Zhengzhou in China (Liu et al., 2012), sustainable land use and urban development in Hong Kong (Shen et al., 2009), land use and land cover change in Daqing City in China (Yu et al., 2011) and in Burkina Faso (Rasmussen et al., 2012), and urban development projects in Seoul, South Korea (Park et al., 2013).

The cellular automata modelling approach, developed in the late 1940s, is based on a twodimensional grid of cells derived from remote sensing images. Each cell represents a land use and a set of transition rules determine its future state based on the values of the neighbouring cells. The utilisation of cellular automata in urban modelling has become a preferred technique since the pioneering work of Tobler (1970), followed by Couclelis (1985), who identified the potential of cellular automata in modelling urban dynamics. The advantages of cellular automata are numerous, namely: flexibility in formulating and generating complex behaviours from simple rules (Lathi, 2008) and an ability to show spatio-temporal dynamics (Sietchiping, 2004). Torrens and O'Sullivan (2001) emphasize that accommodating the incorporation of visualisation capabilities of GIS and remote sensing data makes cellular automata particularly suitable for land use modelling. Nonetheless, cellular automata's simplicity relative to other models (such as ABM) is at the same time a desirable attribute and a significant limitation; and in most cases is inappropriate for modelling complex systems (Iacono et al., 2008). Sietchiping (2004) adds that cellular automata is restricted to general rules and cannot create its own dynamics. Therefore, cellular automata is considered a bottom-up approach that cannot handle human or socio-economic factors (Sietchiping, 2004).

An illustration of cellular automata applications include modelling land use policy in Wuhan China up to the year 2020 (Shi et al., 2012), modelling urban growth at township level in the USA (Al-Kheder et al., 2006), modelling the spread of informal settlements in Cameroon (Sietchiping, 2004), simulating compact development in China (Li et al., 2008), and simulating urban growth in California (Teitz et al., 2005), Australia (Liu and Phinn, 2003), Turkey (Demirel and Cetin, 2010), Dublin (Barredo et al., 2003), Gorgan City, Iran (Mahiny and Gholamalifard, 2007) and Brazil (Almeida et al., 2008). In South Africa, Le Roux (2012) applied the Dyna-Clue cellular automata model to perform urban simulation in Johannesburg to the year 2030. 
$A B M$ s emerged in the 1980 s and are increasingly being adapted by social scientists, especially scientists in urban and geospatial studies, as an effective paradigm for framing the underlying problems of complex and dynamic processes (Chen, 2012). Being grounded on bottom-up processes, that is, from the actions of individual actors to an emerging aggregate level or collective behaviour, ABMs have attracted great attention (Batty, 2009). ABMs model various actors including households relocating their homes, individuals using transport systems, government, and other institutional bodies (Haase and Schwarz, 2009). More sophisticated models incorporating all or some aspects of ABMs include UrbanSim and TRANSIMS. A parallel, but significant approach to individualistic modelling is based on microsimulation which essentially samples individual behaviour from more aggregate distributions and constructs synthetic ABMs linked to spatial location (Clarke, 1996). ABMs have been employed to study urban land use change or growth in Cape Town, South Africa (Shoko and Smit, 2013) and in Dar es Salaam, Tanzania (AugustijnBeckers and Bas Retsios, 2011; Young, 2010).

$S E / E M$ s establish formalised relationships between the population, and related housing market and residential land use (Haase and Schwarz, 2009). These models can be dynamic (when model parameters are treated endogenously) or quasi-dynamic (if model parameters are fixed or exogenous during the modelling exercise). Drivers of change emanate as demand(s) from the population. $\mathrm{SE} / \mathrm{EMs}$ rarely incorporate feedback loops back to the original driver. Compared to the other models reviewed previously, SE/EMs are limited in terms of spatial explicitness, level of dynamism and the ability to incorporate complex arrays of model factors (Haase and Schwarz, 2009). Illustrations of SE/EMs include work by Zeng et al. (2008) who used logistic regression to simulate the spatial patterns of different land use types in Yongding County, Hunan Province, China; and Abebe (2011) who examined the driving forces explaining informal settlement expansion (between 1982 to 2002) and densification (between 1992 to 1998), in Dar es Salaam, Tanzania. Similarly, Cheng and Masser (2003) present a spatial data analysis method to seek and model major determinants of urban growth in the period 1993-2000 through a case study of Wuhan City in the People's Republic of China using logistic regression.

\section{South Africa Urban Growth Modelling Initiatives}

This section reviews the urban modelling initiatives from the 13 completed and returned questionnaires (of the 19 questionnaires sent out), and the limited South African modelling initiatives discovered in the literature review. The urban modelling initiatives were broken down into government (i.e. provincial, municipal and government-funded) and academic initiatives. This summary of South African initiatives, although not exhaustive, provides an indication of the types of urban modelling underway which may form the basis for more accurate and sophisticated urban modelling projects in the future.

The majority of the models described in the completed questionnaires could not be categorised in terms of the five key urban modelling typologies described in the previous chapter. The bulk of the models were GIS-based visualisations of spread sheets that contained future demographic or 
housing projections. Remote sensing studies focusing on historical urban land cover change were also more prevalent than cellular automata for future growth simulations. Apart from the UrbanSim project (reviewed in section 3.3) and limited academic urban simulation research, it can be argued that advanced modelling of urban spatial change within South Africa at an institutional level has not reached a high degree of sophistication. However, Batty (2009) notes a broadening of model styles, types and computer methods on the edge of the urban modelling domain, for example GIS, that in some circumstances may be considered as models when compared to the key urban model types reviewed in the section 2. For this reason, the South African urban modelling typologies were broadened to include GIS-based (i.e. basic GIS analysis tools such as weighted overlays and the visualisation of spread sheet based demographic/housing projections) and remote sensing land cover change models.

\subsection{Provincial government modelling initiatives in Gauteng}

A long standing modelling focus for the Gauteng Provincial Government (GPG) has been transport planning modelling, with the Gauteng Department of Road and Transport (GDRT) commissioning a consortium of transport consultants to undertake transport modelling. At a local metropolitan municipal level, there has been a varied approach to transport modelling with a combination of outsourced and internal modelling and a range of proprietary modelling software, such as EMME2. Sadly, the result is fragmented approaches to modelling, limited modelling capacity and skills development within government, and a mismatch of macro- and micro-scale modelling.

Recognizing the above shortcomings, the GDRT identified the need for integrated land use and transportation planning tools to inform robust decision-making. In response, terms of reference were issued by the GDRT for the establishment of the Gauteng Integrated Transport Modelling Centre (GITMC) with the view to establishing a fully capable and functionally integrated modelling centre for Gauteng, co-ordinating the needs and pooling the resources of both the province and several municipalities (CSIR, 2012). The Council for Scientific and Industrial Research (CSIR), in conjunction with the University of Pretoria was appointed to set up the GITMC as a multi-year project. The GITMC will initially build on the data and modelling generated by the CSIR UrbanSim and MATSim simulation project (discussed in section 3.3) to generate urban growth scenarios based on different transport infrastructure initiatives. The project was in the establishment phase in mid2013, with the training of provincial and municipal staff on the use of UrbanSim and MATSim, but if fully implemented with continued development and innovation of the current UrbanSim data and models, will provide an advanced transport and urban spatial change modelling platform for Gauteng.

Indicative of the current fragmented approach to modelling transport, a parallel transport modelling project is currently underway for the 25-year Integrated Transport Master Plan for Gauteng (ITMP25). In 2012, the GDRT appointed a consortium to take responsibility for the development of the IMTP25. The master plan's core mandate is to enable the GDRT, in 
collaboration with other spheres of government, to regulate, plan and develop an efficient and integrated transport system that serves the public interest by enhancing mobility and delivering safe, secure and environmentally responsible transportation. In October 2012, the first phase of the IMTP25, a five-year short intervention plan designed to serve as a foundation for the IMTP25, alleviate blockages and provide short-term road network and public transport improvements, was submitted to GDRT (GDRT, 2012). A private company, Plan Associates, was assigned the task to update the base land use model for 2010 to the design future years 2015, 2025 and 2037. As of early 2013, there was no collaboration planned between the GITMC and ITMP25 modelling initiatives, highlighting the lack of collaboration and possible duplication of modelling efforts.

To assist with the short- and medium-term integrated planning of education and health facilities within the province, the Gauteng Infrastructure Planning Tool (GIPT) was commissioned by the Gauteng Provincial Treasury and developed in 2012. The tool uses the current location of schools (primary and secondary), hospitals and clinics, to model the future demand and location of new facilities. This provides planners and decision-makers with a tool to analyse different development scenarios and determine the optimal locations for public social facilities (Engelbrecht, 2012). The GIPT utilises a GIS-based model, with three modelling functions developed to determine the candidate locations of the facilities, namely a weighted overlay model; a location allocation analysis and capacity balance model (Engelbrecht, 2012).

The GPC has taken ownership of the GIPT, but it is yet to be implemented or used. During the development, the appointed consultants identified a number of concerns with regard to data and modelling within Gauteng (Kleynhans, 2012). Firstly, there is a vast range of population projections used by GPG departments and no agreement within GPG on which population projections should be used for forward planning. For instance, Gauteng's Census 2011 population of 12272263 exceeds a number of the population projections for the year 2015 utilised by the different departments, highlighting the difficulty of projecting populations in a province of migrants, with serious risks for the under or over provision of facilities. Secondly, integrated planning through the collaboration of the departments involved and implementation of the GIPT will fail if the necessary professional staff are not employed (Kleynhans, 2012).

Finally, the 2011 Gauteng Spatial Development Framework (GSDF) has been developed to provide a clearly defined provincial spatial structure that can accommodate future growth and sustainability within the GCR (GDED, 2011). Five GIS-based models - an urban profile, urban morphology, connectivity, bid rent and virtual model room - were developed to assist in analysing existing urban patterns and dynamics in Gauteng. The five models serve as a basis for future spatial strategies for Gauteng and support policy and planning decisions.

The GSDF was envisaged to be used by all GCR government spheres, non-governmental organisations (NGOs) and private stakeholders through a web GIS tool, but is yet to be made publicly accessible. The official release of the GSDF was slightly delayed due to the Provincial Executive Council decision to rescind the provincial urban edge in favour of the provincial boundary representing the urban edge. This led to a subsequent editing of sections of the GSDF and the consideration of new planning approaches by the GPC to control urban growth. The Gauteng 
Growth Management Strategy is one of the approaches currently under consideration and is intended as a mechanism to enable the GSDF by outlining the planning tools required to manage and direct urban growth towards the desired patterns of growth set out in the GSDF (GPC, 2013). The draft Gauteng Growth Management strategy makes specific mention of the need to set up a joint provincial and municipal urban growth forum, to ensure coordination and cooperation between all stakeholders, and the establishment by the GPG of a growth forecasting and spatial modelling unit, sufficiently staffed and funded to provide a specialised modelling service.

Table 1 provides a description of the provincial initiatives. In summary, the prevailing fragmented modelling approaches within provincial government departments pose a number of challenges in terms of coordinated urban modelling projects in the GCR.

Table 1. Provincial government urban modelling initiatives in Gauteng

\begin{tabular}{lll}
\hline Model & Model Type & Main purpose/description \\
\hline GITMC & Econometric/micro-simulation/ABM & $\begin{array}{l}\text { CSIR, in conjunction with University of Pretoria, } \\
\text { appointed by GDRT to establish the GITMC with } \\
\text { the aim of coordinating and integrating transport } \\
\text { modelling for local and provincial governments in } \\
\text { Gauteng. }\end{array}$ \\
& &
\end{tabular}

Gauteng ITMP25 GIS-based with linked spread sheets

land use modelling

\section{Gauteng}

Infrastructure

Planning Tool

\author{
GIS-based models (weighted overlay \\ and location allocation analysis) with \\ linked spread sheets
}

The 2010 transportation model (base year 2007) for land use updated to the 2010 base year and design years 2015, 2025, and 2037 for the IMTP25.

Developed to assist with the short- and mediumterm integrated planning of education and health facilities within the province.

GSDF

GIS-based models

Five models were developed to assist in analysing existing urban patterns and dynamics in Gauteng as a whole, as well as serving as a basis for future spatial strategies for the province, and supporting policy and planning decisions.

\subsection{Municipal government modelling initiatives}

This section discusses the various modelling initiatives of three metropolitan municipalities, i.e. City of Cape Town, eThekwini and City of Johannesburg (see Table 2). UrbanSim modelling of Ekurhuleni, eThekwini and Nelson Mandela Bay are covered in more detail in the CSIR UrbanSim project write up in the next section.

The City of Cape Town uses a range of methods, tools and data to monitor urban spatial change. Two of the key models or systems used to monitor urban growth and estimate how much land is required for the city's growth are the Urban Growth Model (UGM) and Urban Growth Monitoring System (UGMS) (City of Cape Town, 2012a; 2012b). The GIS-based UGM is used to model urban growth by mapping where the growth is likely to occur. In addition, the UGM estimates residential 
dwelling units and future industrial and mixed-use land use. The outputs from the UGM assist in planning for future municipal service investment requirements. With the help of an external consultant, the city has built a spatially-explicit UGMS used to provide up-to-date urban growth information and monitor urban growth (i.e. rates, patterns, and direction). The UGMS is also used to inform the Integrated Development Plan (IDP), Spatial Development Framework (SDF) and other city policies.

The eThekwini municipality is involved in numerous modelling projects which assess the impacts of various municipal projects on the spatial development trajectory of the municipality. The Infrastructure Investment Finance Model is a spread sheet-based model linked to maps that tracks and predicts the infrastructural impacts of land uses as per the municipality's spatial development plans. It determines the extent and costs of the required infrastructure and how these costs affect the municipality's capital expenditure and operating revenue portfolios. The Accessibility model is also GIS-based and used to understand the future social services requirements of the municipality's housing planning projects. The model simulates the supply of and demand for social facilities based on population numbers, incomes, and age profiles. According to Breetzke (2009), they are not really simulation models, but rather 'assessment tools'.

Similarly, City of Johannesburg's modelling projects rather than simulate scenarios are designed to track trends and the impacts of various land use developments. The projects include monitoring development trends for the Growth Management Strategy (GMS) and the urbanisation plan. The development trends project is spread sheet-based (linked to maps) and monitors development trends through the capture and analysis of building and township planning applications. The development trends are used to check if the city's spatial development framework is matching the infrastructure investments the city is making in terms of its GMS. The city's Sustainable Human Settlement Urbanisation Plan (SHSUP) - commonly referred to as the urbanisation plan - was formulated to guide the city's spatial development (CoJ, 2012a). The plan is intended to consider where to locate new additional households, appropriate densities for new housing, the impacts on physical and social amenities, and the required planning initiatives and land acquisitions. The urbanisation plan model is spread sheet-based projecting future housing demands, with $3 \mathrm{D}$ visualisations of the densification projections in key development corridors produced with Esri's CityEngine software (CoJ, 2012b).

Table 2. Municipal government modelling initiatives

\begin{tabular}{lll}
\hline Model & Model Type & Main purpose/description \\
\hline $\begin{array}{l}\text { City of } \\
\text { Johannesburg: } \\
\begin{array}{l}\text { Development } \\
\text { trends }\end{array}\end{array}$ & Spread sheet-based with GIS maps & $\begin{array}{l}\text { Monitoring development trends through the capture } \\
\text { and analysis of building and township planning } \\
\text { applications. The development trends are used to } \\
\text { check if the city's spatial development framework is } \\
\text { matching the infrastructure investments that the city } \\
\text { is making in terms of its GMS. }\end{array}$ \\
\hline Urbanisation model & $\begin{array}{l}\text { Spread sheet-based with 3D GIS } \\
\text { visualisations }\end{array}$ & $\begin{array}{l}\text { An urbanisation plan intended to guide the city's } \\
\text { spatial development, especially with the housing }\end{array}$ \\
\hline
\end{tabular}


needs of the ever burgeoning number of city households.

\begin{tabular}{lll}
\hline $\begin{array}{l}\text { eThekwini: } \\
\text { Infrastructure }\end{array}$ & Spread sheet-based with GIS maps & $\begin{array}{l}\text { Tracks and predicts infrastructural impacts of land } \\
\text { uses as per the municipality's spatial development } \\
\text { Investment Finance } \\
\text { Model }\end{array}$ \\
& GIS-based & $\begin{array}{l}\text { required infrastructure and how these costs affect the } \\
\text { municipality's capital expenditure and operating } \\
\text { revenue portfolios. }\end{array}$ \\
\hline $\begin{array}{l}\text { Accessibility } \\
\text { model }\end{array}$ & GIS-based & $\begin{array}{l}\text { A spatially-explicit model used to understand the } \\
\text { future social services requirements of the } \\
\text { municipality's housing planning projects. }\end{array}$ \\
\hline $\begin{array}{l}\text { City of Cape } \\
\text { Town: }\end{array}$ & $\begin{array}{l}\text { Models future growth directions by estimating } \\
\text { residential, industrial and mixed-use land } \\
\text { requirements, spatially and over time. Also estimates } \\
\text { the city services' investment needs. }\end{array}$ \\
\hline UGMS & GIS-based & $\begin{array}{l}\text { Used to provide up-to-date urban growth information } \\
\text { and monitor urban growth (i.e. rates, patterns, and } \\
\text { direction). Also used to inform IDP and SDFs. }\end{array}$ \\
\hline
\end{tabular}

\subsection{Other government-funded modelling initiatives: CSIR}

The CSIR's Built Environment unit established an Urban Dynamics Laboratory (UDL) in 2007 to 'bring together a trans-disciplinary team and a package of tools and methodologies in a numerical modelling and simulation capability to study cities and regions as complex, social-ecological systems with emergent behaviour' (Waldeck, 2007, 5).

Following a comprehensive literature review of international urban modelling, the CSIR recommended the use of the UrbanSim modelling system (Waldeck, 2007). UrbanSim, developed by Waddell (2002), is a land use model incorporating microsimulations of demographic processes; land use development; parcel-level land use representation and high level of household type disaggregation (Waddell et al., 2003). The first major application of CSIR's urban simulation capability formed part of the Integrated Development Planning and Modelling Project (IDPM), funded by the National Department of Science and Technology (DST) (CSIR, 2011). The IPDM forms part of the broader stepSA (spatial temporal evidence for planning South Africa) project, a collaborative initiative commissioned by DST, in partnership with the CSIR and the Human Sciences Research Council (HSRC), in support of integrated development and spatial planning across sectors and scales (stepSA, 2013a). The simulation project in the cities of eThekwini, Nelson Mandela Bay and Johannesburg, and Gauteng province, is studying the likely patterns of urban growth 30 years into the future by modelling the impact of current spatial policy and investment decisions. A separate modelling initiative which forms part of the Water Sustainability Flagship Programme of the CSIR is currently underway in Ekurhuleni Metropolitan Municipality. The urban growth simulation will focus on future demand and consumption patterns for wastewater and sanitation in Ekurhuleni. The modelling is expected to inform waste water infrastructure investment decisions (stepSA, 2013b). 
The simulation platform chosen by CSIR for the above projects is a combination of UrbanSim, for the microsimulation of choices of households and businesses in relation to property and services, developers as suppliers of services and government providing infrastructure and services; and MATSim, an open source agent-based traffic simulation software for simulation of transportation system behaviour from an individual household perspective (CSIR, 2010; CSIR, 2011). UrbanSim and MATSim share some of the source data, but ultimately run independently of each other, exchanging feedback information after each year of simulation. Flow map, a software package that analyses flow or interaction data, is also used for the catchment area analysis, proximity counting and optimisation components of the modelling. Figure 2 illustrates the interaction of these agents in the urban property market; with the choices and model components of households, businesses and developers (including government).

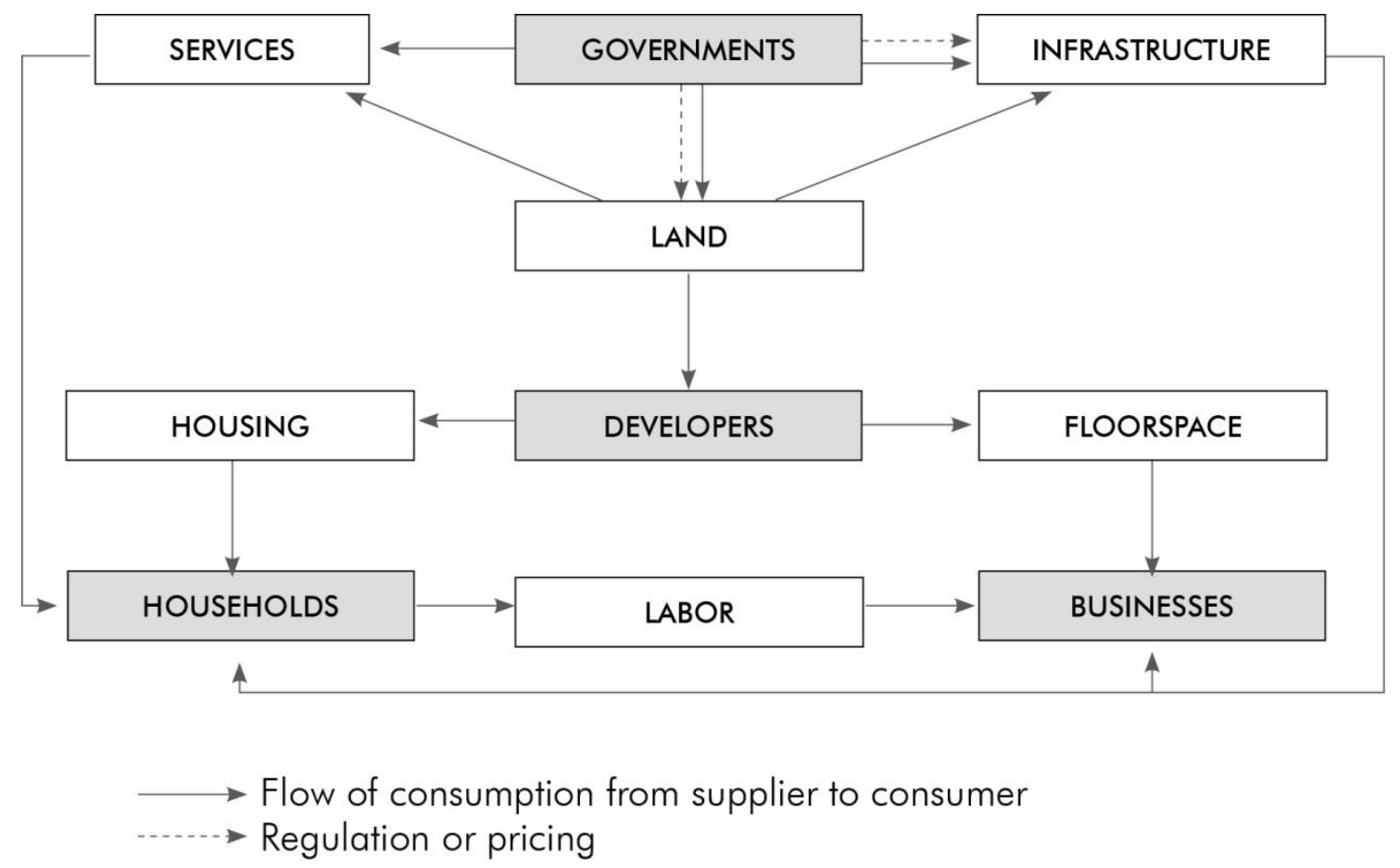

Figure 2. UrbanSim model agents interacting in urban markets (Source: Waddell $(2011,10)$ )

Two of the key challenges experienced by the CSIR, and ultimately a test of whether urban simulation and the UrbanSim platform can be applied in a developing country context were: i) configuring UrbanSim to a South African urban environment to account for unique developing country housing typologies, such as informal settlements and backyard accommodation; and ii) problems obtaining data, such as public transport routes and schedules, that can be utilised at an ABM/micro-simulation scale. This has required the customisation of the UrbanSim model for the unique South African urban development context and an ongoing search for suitable public transport data.

Despite these constraints the simulation was successfully tested in the three cities. In the case of Nelson Mandela Bay the model was used to predict the location of backyard structures and the viability of public transport routes. Similarly in Johannesburg the model revealed the prominence of 
backyard structures and the likely occurrence of housing densification outside the planned public transportation areas. Residential growth in eThekwini was also predicted to occur outside of the planned development corridors and the model predicted that the current and future planned densification within these corridors would be not enough to support public transport (CSIR, 2014). The simulation results have, therefore, provided valuable simulations for city planners to consider during the drafting and evaluation of their city's long term development plans.

Table 3. Government-funded CSIR urban modelling

\begin{tabular}{lll}
\hline Model & Model Type & Main purpose/description \\
\hline CSIR & $\begin{array}{l}\text { Econometric/micro- } \\
\text { simulation/ABM }\end{array}$ & $\begin{array}{l}\text { Simulates urban growth 30 years into the future in eThekwini, Nelson } \\
\text { Mandela Bay and Johannesburg, based on current spatial policy and } \\
\text { investment decisions. UrbanSim models are also being developed for the } \\
\text { GITMC and Ekurhuleni. }\end{array}$ \\
\hline
\end{tabular}

\subsection{Academic modelling initiatives}

This section will highlight recent urban change/growth modelling initiatives in the South African academic research context identified in the returned questionnaires and literature review.

A number of research institutions, have assessed historical urban land cover change over time using remote sensing and GIS. The studies focused mainly on historical change (from one to 10 years) and not the simulation of future land use change. The software used includes eCognition, ENVI, ERDAS and Esri ArcGIS. More recent examples include Haywood (2013), who utilized Landsat imagery for a 38-year period to investigate rate of land cover patterns in the Richards Bay area, and Mubiwa and Annegarn's (2013) land cover/use change analysis in the GCR between 1991 and 2009 (see Table 4).

Limited examples of future urban growth simulations in South Africa were found in academia. Using the Dyna-Clue cellular automata model, Le Roux (2012) simulated the consequences of the City of Johannesburg's proposed land use policies by comparing the spatial impact of two different scenarios to determine whether spatial equality will be restored to the city by the year 2030 . Shoko and Smit (2013) used ABM to analyse informal settlements in the City of Cape Town. Cilliers (2010) used a spatial Multi-Criteria Analysis to derive empirical results used as inputs for a future urban growth scenario to the year 2030 for the city of Potchefstroom located in the Tlokwe local municipality, North West Province.

Other initiatives include the South African Research Chair in Development Planning and Modelling research programme, funded by the National Research Foundation and based at the University of Witwatersrand, Johannesburg, was established in 2009. Its broad research area is to describe, analyse, model and explain the shifting spatial order of a dynamic GCR, with a focus on the role of development planning and other policies, processes and instruments in shaping spatial outcomes. 
The Centre for Regional and Urban Innovations and Statistical Exploration (CRUISE), based at the University of Stellenbosch, relies on systems theory to examine spatial relationships and the various social, economic and ecological sustainability processes that occur in cities. This is intended to bring about a greater understanding of the operation of cities as systems. The centre focuses on cities' urban form, functional linkages and formal and informal linkages.

Table 4. Academic urban modelling research examples

\begin{tabular}{|c|c|c|}
\hline Author/institution & Model Type & Main purpose/description \\
\hline Haywood $(2012,2013)$ & $\begin{array}{l}\text { Remote } \\
\text { sensing land } \\
\text { cover change }\end{array}$ & $\begin{array}{l}\text { Investigation of land cover patterns to determine rate of land cover } \\
\text { change in Richards Bay from } 1973 \text { to } 2011 \text {. The study revealed } \\
\text { significant urban growth following the development of the harbour } \\
\text { in } 1976 .\end{array}$ \\
\hline Mubiwa and Annegarn, (2013) & $\begin{array}{l}\text { Remote } \\
\text { sensing land } \\
\text { cover change }\end{array}$ & $\begin{array}{l}\text { Urban land cover change in the GCR. The study comprised of two } \\
\text { parts: (i) a description of the evolution of urban spatial development } \\
\text { between the 1890s and 1990; (ii) a detailed analysis of land use/land } \\
\text { cover changes and urban development from } 1991 \text { to } 2009 \text {. }\end{array}$ \\
\hline Le Roux (2012) & $\begin{array}{l}\text { Cellular } \\
\text { automata } \\
\text { (Dyna-Clue) }\end{array}$ & $\begin{array}{l}\text { An investigation into the consequences of the City of } \\
\text { Johannesburg's current planning policies using the cellular automata } \\
\text { Dyna-Clue model. Compares as-is scenario, assuming continued } \\
\text { growth, versus implementation of land use policies and strategies to } \\
\text { limit growth, promote densification and build low cost housing in } \\
\text { accessible locations. }\end{array}$ \\
\hline Shoko and Smit (2013) & $\mathrm{ABM}$ & $\begin{array}{l}\text { Patterns and trends in land occupation change over time in an } \\
\text { informal settlement in Cape Town. }\end{array}$ \\
\hline $\begin{array}{l}\text { South African Research Chair } \\
\text { in Development Planning and } \\
\text { Modelling, University of the } \\
\text { Witwatersrand }\end{array}$ & $\begin{array}{l}\text { Standard and } \\
\text { spatial } \\
\text { regression }\end{array}$ & $\begin{array}{l}\text { Established in } 2009 \text {, this research centre is currently focusing on } \\
\text { describing, analysing, and explaining the shifting spatial order of a } \\
\text { dynamic GCR, with an emphasis on the role of development } \\
\text { planning and other policies, processes and instruments in shaping } \\
\text { spatial outcomes. }\end{array}$ \\
\hline $\begin{array}{l}\text { CRUISE, University of } \\
\text { Stellenbosch }\end{array}$ & Various & $\begin{array}{l}\text { The centre focuses on research that examine the spatial relationships } \\
\text { and the various social, economic, and ecological sustainability } \\
\text { processes that occur in cities. }\end{array}$ \\
\hline
\end{tabular}

\section{Key Urban Modelling Challenges and Potential Opportunities Facing the GCR}

The previous section described the variety of urban modelling initiatives or tools currently utilised in South Africa. These range from Excel spread sheet population projections, GIS-based visualisations and spatial models, land cover change analysis and complex urban growth simulation models using the UrbanSim platform. Ultimately, the modelling initiatives should be utilised for testing different policy options and to provide guidance for long-term planning and policy, such as 
assessing the proposed G2055 interventions. This section, therefore, discusses various key challenges and potential opportunities for urban modelling in the GCR in more detail.

\subsection{Key urban modelling challenges facing the GCR}

There is an urgent need to streamline and coordinate the various modelling efforts currently underway in the GCR and South Africa. Within Gauteng, each of the metropolitan municipalities City of Johannesburg with the Joburg GDS (Growth Development Strategy) 2040 (CoJ, 2013), Ekurhuleni with Ekurhuleni GDS 2055 (Ekurhuleni, 2013) and City of Tshwane with Tshwane 2055 (CoT, 2013) - and GPG with G2055, are working on long-term planning or growth development/management strategies. At the national level, the National Development Plan 2030 formulated by the National Planning Commission (NPC), has been adopted by the South African government (NPC, 2012). As these long-term strategies grapple, among others, with understanding future urban forms, a coordinated effort is required to ensure any models developed within each of the frameworks work together off a common base. For example, in the Gauteng provincial context, a number of tools and models within GPG departments are using different base data or population projections. There is a strong likelihood of the different models producing diverse results. Further research is required to establish a commonly accepted set of future population figures that can be used as a population control total for the various models and tools in the GCR and the country at large.

Furthermore, there is a degree of duplication with a number of departments/institutions modelling the same output. For example, the GIPT (reviewed in section 3.1) and the National Human Settlements Land Index developed by the Housing Development Agency (HDA), both identify land suitable for the development of public infrastructure, such as housing, schools and hospitals. The land suitability models have been constructed using different methodologies and there should be discussion and agreement regarding the methodologies, or at the very least a comparison and sharing of the results. To fully realise the vision of various long-term strategies, an integrated modelling approach is required. Simply put, collaborative models + open data + integrated systems $=$ smarter cities/regions.

A central, freely accessible GIS geodatabase with the key base data layers required for urban modelling is crucial to ensure the same up-to-date base datasets are available for every Gauteng modelling project. This is a critical requirement, as within Gauteng, provincial spatial data is not easily accessible publicly and is often only available to other provincial and local departments through personal relationships (Wray and van Olst, 2012). One of the objectives of the South African Spatial Data Infrastructure Act (SASDI) is to 'promote the use and sharing of spatial information in support of spatial planning, social-economic development and related activities' (RSA, 2004). This has yet to be effectively applied in Gauteng. In 2008, the GPG proposed a GIS for the GCR, referred to as GeoGCR, to fundamentally transform provincial information service delivery (GDED, 2008; Kekana, 2010). However, after six years and despite various plans, the project has yet to be implemented. There is a need for a co-ordinated Spatial Data Infrastructure 
(SDI) within the GCR that would not only fulfil the objectives of SASDI, but also play a role in urban modelling. We suggest that the relevant institutions mandated to bring the GeoGCR into reality work harder towards achieving this crucial SDI objective.

An additional challenge is how to model not only the Gauteng province, but the wider GCR which overlaps into neighbouring provinces. The dynamic relationships external to Gauteng need to be considered in any long-term strategic plan or model claiming to have a city-regional focus. None more so than the transport modelling which should be considering both internal and external traffic flows within and into the province. For example, the swathe of semi-urban settlements situated in the Thembisile and J.R. Moroka local municipalities in Mpumalanga on the north-eastern border of Gauteng is functionally connected to the Gauteng economy by subsidised bus transport routes, which have historically ferried thousands of workers into central Pretoria on a long-distance daily commute. However, modelling across such an immense extent raises a range of issues that need to be considered, such as data availability and the application of an appropriate modelling scale.

\subsection{Key Urban modelling opportunities in the GCR}

This section highlights key modelling potential opportunities in the GCR and starts by discussing how the various long-term planning initiatives can benefit from the existing urban modelling projects. A range of short- and medium-term priorities for integrated modelling in the GCR is also discussed. We argue that refining the various models that already exist for South Africa and the GCR can serve as a starting point for informing long-term planning, rather than duplicating efforts. The model refinement process should include improving the process of developing, validating, extending, and applying models; and supporting their effective use in long-term projects, such as G2055, the Gauteng Growth Management Strategy and municipal growth development strategies. This should include: improving data collection so that the quality of data available is enhanced; agreement and use of a common set of population projections; and ensuring a participatory process for the modelling work. The joint provincial and municipal urban growth forum and growth forecasting and spatial modelling unit proposed by the draft Gauteng Growth Management Strategy should address the majority of the issues identified by this paper, such as improving data collection so that the quality of data available is enhanced; agreement and use of a common set of population projections; and ensuring a participatory process for the modelling work.

An example of possible modelling projects for the GCR is drawn from the G2055 planning process. In response to the strategic pathways defined in the $\mathrm{G} 2055$ planning process, a range of demographic and spatial modelling priorities were identified by GCR stakeholders in 2012. Stakeholders included the Gauteng City-Region Observatory (GCRO), GPC, CSIR, HDA and representatives from the municipalities within Gauteng. The need to explore the new Census data in more detail and update the models with the latest Census 2011 data were identified as short-term priorities for demographic modelling. Longer-term priorities included the need for more research and modelling to understand household densities and the number of schools and clinics required to meet future population growth. In terms of spatial modelling priorities identified by the 
stakeholders, a short-term simulation project was proposed to evaluate whether there is enough well-located land to cater for future housing development within Gauteng. Medium- to longer-term priorities included: modelling development corridors based on various policy options; a 3D visualisation of GCR's future urban form; and modelling cross-municipal infrastructure and transport networks. The CSIR's UrbanSim platform was highlighted as a possible modelling platform.

In line with the GCR's modelling priorities identified above, we therefore suggest a number of factors that must be considered. We suggest the urgent establishment of the GeoGCR GIS database and SDI, highlighted in the previous section as a key challenge. This is seen as a priority to ensure access to spatial data and use of the same base data by the GCR stakeholders. Another factor is the continuous refinement and use of temporal or up-to-date data. The latest Census 2011 data provides an opportunity to update and recalibrate the models with accurate up-to-date demographic variables. With three sets of Census data now available (1996, 2001 and 2011), detailed trends analysis and projections are also possible with data at a detailed small area layer or sub-place level.

We further believe that once the GeoGCR geodatabase is operational there are opportunities to utilise the outputs from some of the models for multiple applications at multiple scales. The CSIR UrbanSim project, for example, produces a spatial location of future population (in the form of the location of new housing) for each year of the simulation run. These results could feed into the GIPT to improve the accuracy of locating future facilities based on a more precise location of the future population. A high level of coordination and agreement is required to achieve this, and similar to the stepSA initiative at national level, a planning/modelling networking group within the GCR is called for - a role the GeoGCR team, joint growth management forum and/or growth forecasting and spatial modelling unit (as proposed by the draft Gauteng Growth Management Strategy) should fulfil once established.

A national spatial observatory, proposed in the National Development Plan 2030, represents yet another opportunity for data analysis and modelling coordination on a national scale, as its mandate is to collect, integrate and manage information from various national departments and agencies (NPC, 2012). The successful implementation of a national spatial observatory will be key to strengthening and integrating data analysis and modelling across South Africa, with national models feeding into city-regional and city-level modelling work. However, careful consideration must be given to the possible overlapping roles and work of the national spatial observatory and the stepSA programme.

There is also scope for the development of modelling skills at a tertiary level and on-going research into the application of urban change and simulation models in a developing country context. The highly technical, data hungry and complex UrbanSim model represents the top-end of urban simulation. In contrast, cellular automata simulations or newly developed morphological approaches to predicting urban expansion (Arsanjani et al., 2013) may provide a quicker simpler representation of the future urban form, offering a multi-scaled approach to modelling and guiding policy in the GCR. Research projects in this area, in conjunction with local and provincial government planning departments, should be encouraged. 


\section{Conclusion}

Urban modelling provides important tools for urban spatial planning, management and the simulation of future development. At the same time, we emphasize the need for understanding that models inform policy and are not crystal balls that can magically predict the future. Rather, they present an opportunity to test the possible implications of different policy scenarios and interventions. Decisions on urban spatial planning have to be made utilising the best available information and modelling processes.

Internationally, section 2 highlighted the wide range of urban spatial change models successfully applied in a number of countries to assist with long-term planning. In the South African context, apart from the CSIR UrbanSim project and limited academic urban simulation research, we argue that advanced modelling of urban spatial change at an institutional level has not reached a high degree of sophistication. Local and provincial modelling projects are mainly GIS-based visualisations, tracking trends rather than simulating future scenarios, with future modelling based on population projections. There is also a risk that out-dated data, different population projections, duplicated tools, limited SDU and a lack of resources; could compromise urban spatial change modelling efforts within government institutions. Provided there is open access to the latest spatial data, coordinated modelling efforts and an effective SDI in place across all government initiatives within Gauteng, GIS can play a critical part in urban modelling by providing the base geodatabases and first phase of analysis as the initial input into more complicated models.

The majority of the academic projects reviewed were not future urban growth simulation models, but analyses of historical land cover change. These however, could be expanded into urban growth simulation models, for example, by utilising historical data identified in Mubiwa and Annegarn's (2013) land cover change research and applying cellular automata simulation techniques. In addition, the few examples of cellular automata simulation research focusing on urban growth in Johannesburg as well as the various modelling projects at the South African Research Chair in Development Planning and Modelling and CRUISE provide scope for the on-going development of complex modelling projects and modelling skills at a tertiary level. We also note that whereas CSIR UrbanSim project has been funded by a national department, it has now been expanded to the GDRT as part of the GTIMC. As such, there is an opportunity to utilise the UrbanSim project to benefit long-term planning, such as the G2055 project or as part of a growth forecasting and spatial modelling unit proposed by the draft Gauteng Growth Management Strategy.

We finally conclude that provided the key challenges described in the paper are addressed, there are numerous opportunities for modelling urban spatial change in the GCR and South Africa as a whole. This is with an understanding that urban models across the world in general, and in the GCR in particular, provide platforms for joint learning in understanding the effects of the long-term planning policy scenarios and interventions as means towards solving future urban problems. 


\section{Acknowledgments}

This paper draws from the GCRO Occasional Paper 6: Modelling urban spatial change: a review of international and South Africa modelling initiatives.

\section{References}

Abebe, FK 2011, 'Modelling informal settlement growth in Dar es Salaam', Unpublished Master's Thesis, University of Twente, the Netherlands.

Ahmad, S \& Simonovic, SP 2004, 'Spatial system dynamics: new approach for simulation of water resources systems', Journal of Computing and Civil Engineering, vol. 18, no. 4, pp. 331-340.

Akiva, B \& Lerman, S 1985, Discrete Choice Analysis: Theory and Application to Travel Demand, MIT Press, Cambridge, MA.

Al-Kheder, S, Wang, J \& Shan, J 2006, 'Change Detection-cellular automata method for urban growth modelling', ISPRS Commission VII Mid-term symposium "Remote sensing: from pixels to processes", Enschede, the Netherlands, 8-11 May.

Almeida, CM, Gleriani, JM, Castejon, EF \& Soares-Filho, BS 2008, 'Using neural networks and cellular automata for modelling intra-urban land-use dynamics', International Journal of Geographical Information Science, vol. 22, no. 9, pp. 943-963.

Arsanjani, JJ, Helbich, M \& Mousivand, AJ 2013, 'A Morphological approach to predicting urban expansion', Transactions in GIS, in press (early online version), viewed 2 July 2013, http://onlinelibrary.wiley.com/doi/10.1111/tgis.12031/abstract.

Augustijn-Beckers, E \& Bas Retsios, JF 2011, 'Simulating informal settlement growth in Dar es Salaam, Tanzania: an agent-based housing model', Computers, Environment and Urban Systems, vol. 35, no. 2, pp. 93-103.

Barredo, JI, Kasanko, M, McCormick, N \& Lavelle, C 2003, 'Modelling dynamic spatial processes: Simulation of urban future scenarios through cellular automata', Landscape and Urban Planning, vol. 64, no.3, pp. 145-160.

Batty, M 2008, 'Fifty years of urban modelling: macro-statics to micro-dynamics', in S Albeverio, D Andrey, P Giordano and A Vancheri (eds.), The dynamics of complex urban system. Physica- Verlag, Heidelberg.

Batty, M 2009, 'Urban modelling', in N Thrift and R Kitchin (eds.), International Encyclopaedia of Human Geography, Elsevier, Oxford.

Berling-Wolff, S \& Wu, J 2004, 'Modelling urban landscape dynamics: a review', Ecological Research, vol. 19, no. 1, pp. 119-129.

Breetzke, K 2009, From Conceptual Frameworks to Quantitative Models: Spatial Planning in the Durban Metropolitan Area, South Africa - The Link to Housing and Infrastructure Planning. Case Study Prepared for Planning Sustainable Cities: Global Report on Human Settlements, viewed 15 January 2013, http://www.unhabitat.org/grhs/2009.

Chang, J 2006, 'Models of the relationship between transport and land-use: a review', Transport Reviews: A Transnational Transdisciplinary Journal, vol. 26, no. 3, pp. 325-350.

Chen, L 2012, 'Agent-based modelling in urban and architectural research: a brief literature review', Frontiers of Architectural Research, vol. 1, no. 2, pp. 166-177.

Cheng, J \& Masser, V 2003, 'Urban growth pattern modelling: A case study of Wuhan city, PR China', Landscape and Urban Planning, vol. 62, no. 4, pp. 199-217.

Cilliers, DP 2010, 'The development and use of a land-use suitability model in spatial planning in South Africa', Unpublished Masters' Thesis, North West University, South Africa.

City of Cape Town 2012a, 'Using the growth model', Cape Town, South Africa. 
South African Journal of Geomatics, Vol. 4, No. 1, February 2015

City of Cape Town 2012b, 'Urban growth monitoring system - UGMS', Cape Town, South Africa.

City of Johannesburg (CoJ) 2012a, 'Sustainable Human Settlements Urbanisation Plan' (Presentation to the Executive Management Committee Department of Development Planning, Johannesburg, South Africa), 23 July.

City of Johannesburg (CoJ) 2012b, 'Changing Course: Unconventional Solutions for an Unconventional City' (City future presentation, Johannesburg, South Africa), 29 October.

City of Johannesburg, (CoJ) 2013, Joburg GDS 2040 strategy, viewed 15 May 2013, http://www.joburg.org.za/index.php?option=com_content\&id=7343\&Itemid=114\&limitstart=1 .

City of Tshwane (COT) 2013, Tshwane vision 2055, viewed 15 May 2013, http://www.tshwane2055.gov.za/home/tshwane-2055-info/tshwane-vision-2055.

Clarke, G 1996, Microsimulation for urban and regional policy analysis, Pion Press, London.

Couclelis, H 1985, 'Cellular worlds: a framework for modelling micro-macro dynamics', Environment \& Planning A, vol. 17, no. 5, pp. 585-596.

CSIR (Council for Scientific and Industrial Research) 2010, 'OECD research on contemporary urban models: Questionnaire', CSIR, Pretoria, South Africa.

CSIR (Council for Scientific and Industrial Research) 2011, 'Research aids sustainable planning of cities 30 years ahead', Sciencescope, vol. 5, 18-19.

CSIR (Council for Scientific and Industrial Research) 2012, 'Gauteng Integrated Transport Modelling Centre: Draft Institutional Framework', CSIR Built Environment, Pretoria, South Africa.

CSIR (Council for Scientific and Industrial Research) 2014, Living lab case studies, viewed 28 August 2014, http://stepsa.org/urban-spatial-transformation/urban-futures/spatial-outcomes-of-planningscenarios/living-laboratories/living-lab-case-studies.

Demirel, H \& Cetin, M 2010, 'Modelling urban dynamics via cellular automata', ISPRS Archive vol. XXXVIII-4-8-2/W9. Core spatial databases - updating, maintenance and services - from theory to practice, Haifa, Israel, 15-17 March.

Engelbrecht, G 2012, 'Infrastructure Planning Tool', GISSA Ukubuzana 2012 conference, Ekurhuleni, 2-4 October 2012, pp. 68-80, GISSA.

Ekurhuleni 2013, GDS 2055, viewed 15 May 2013, http://www.ekurhuleni.gov.za/gds2055.

Forrester, JW 1969, Urban Dynamics, MIT Press, Cambridge, MA.

GCRO (Gauteng City-Region Observatory) 2011, The City-Region Review 2011, GCRO, Johannesburg, South Africa.

GCRO (Gauteng City-Region Observatory) 2012, 'Key Findings from Statistics South Africa's 2011 National Census for Gauteng - GCRO Data brief: No.1 of 2012', GCRO, Johannesburg, South Africa.

GDED (Gauteng Department of Economic Development) 2008, 'GeoGCR - Draft Concept Plan October 2008', Gauteng Provincial Government, Johannesburg, South Africa.

GDED (Gauteng Department of Economic Development) 2011, 'The Gauteng Spatial Development Framework - February 2011', Gauteng Provincial Government, Johannesburg, South Africa.

GDRT (Gauteng Department of Roads and Transport) 2012, Gauteng's new 5-Year Transport Plan, viewed 15 February 2013, http://www.gautengonline.gov.za/MediaStatements/Pages/Gautengsnew5yearTransportPlan.aspx.

Giere, RN 2004, 'How are Models used to Represent Reality?' Philosophy of Science, vol. 71, no. 5, pp. $742-752$.

GPC (Gauteng Planning Commission) 2012, 'Gauteng 2055: A Discussion Document on the Long-Term Development Plan for the Gauteng City-Region', Gauteng Provincial Government, Johannesburg, South Africa.

GPC (Gauteng Planning Commission) 2013, 'Gauteng Growth Management Strategy. Draft for Comment June 2013', Gauteng Provincial Government, Johannesburg, South Africa. 
Haase, D \& Schwarz, N 2009, 'Simulation Models On Human-Nature Interactions in Urban Landscapes: A Review including Spatial Economics, System Dynamics, Cellular Automata and Agent-Based Approaches', Living Review Landscape Research, vol. 3, no. 2, pp. 1-45.

Haghani, A, Lee, SY \& Byun, JH 2003, 'A system dynamics approach to land use/transportation system performance modelling Part I: Methodology’, Journal of Advanced Transportation, vol. 37, no.1, pp. 141.

Haywood, Q 2013, 'Investigating changes in land cover patterns in the Richards Bay area', PositionIT, July, pp. 36-42.

Iacono, M, Levinson, D \& El-Geneidy, A 2008, 'Models of transportation and land use change: a guide to the territory', Journal of Planning Literature, vol. 22, no. 4, pp. 323-340.

Kekana, A, 2010 'GeoGCR Concept Plan: Presentation at the Launch of the GCRO GIS Website - 1 September 2010', Gauteng Provincial Government, Johannesburg, South Africa.

Kleynhans, PJ 2012, 'The Provision of Short-Term Technical Assistance Services to the Gauteng Provincial Treasury: Closure Report - Version 2', Mogwariepa Consulting CC, Johannesburg, South Africa.

Lathi, J 2008, 'Modelling urban growth using cellular automata: a case study of Sydney, Australia', Unpublished Masters' Thesis, International Institute for Geo-Information Science and Earth Observation (ITC), The Netherlands.

Le Roux, A 2012, 'Quantifying the spatial implications of future land use policies in South Africa: reshaping a city through land use modelling', Unpublished Masters' Thesis, ITC, The Netherlands.

Li, X, Yang, Q \& Liu, X 2008, 'Discovering and evaluating urban signatures for simulating compact development using cellular automata', Landscape and Urban Planning, vol. 86, no. 2, pp. 177-186.

Liu, H, Guo, HC, Sheng, H, Du, XS, Li, N \& Yang, YH 2012, 'The application of system dynamics method in environmental impact assessment of planning in airport zone', Zhongguo Huanjing Kexue/China Environmental Science, vol. 32, no.5, pp. 933-941.

Liu, Y \& Phinn, RS 2003, 'Modelling urban development with cellular automata incorporating fuzzy-set approaches', Computers, Environment and Urban Systems, vol. 27, no. 6, pp. 637-658.

Mahiny, AS \& Gholamalifard, M 2007, 'Dynamic spatial modelling of urban growth through cellular automata in a GIS environment', International Journal Environment Research, vol. 1, no. 3, pp. 272-279.

Mubiwa, B and Annegarn, H 2013, Historical spatial change in the Gauteng City-Region, (GCRO Occasional Paper 4), GCRO, Johannesburg, South Africa.

NPC (National Planning Commission), 2012 Our Future: Make It Work: National Development Plan 2030, viewed 23 May 2013, http://www.npconline.co.za.

Park, M, Kim, Y, Lee, H-S, Han, S, Hwang, S \& Choi, MJ 2013, "Modelling the dynamics of urban development project: Focusing on self-sufficient city development', Mathematical and Computer Modelling, vol. 57, no. 9-10, pp. 2082-2093.

Pfaffenbichler, P, Emberger, G \& Shepherd, S 2008, 'The Integrated Dynamic Land Use and Transport Model MARS', Networks and Spatial Economics, vol. 8, no. 2-3, pp. 183-200.

Rasmussen, LV, Rasmussen, K, Reenberg, A \& Proud, S 2012. 'A system dynamics approach to land use changes in agro-pastoral systems on the desert margins of Sahel', Agricultural Systems, vol. 107, pp. 5664.

RSA (Republic of South Africa) 2004, Spatial Data Infrastructure Act, No. 54 of 2003, Government Gazette, Cape Town.

Shen, Q, Chen, Q, Tang, BS, Yeung, S, Hu, Y \& Cheung, G 2009, 'A system dynamics model for the sustainable land use planning and development', Habitat International, vol. 33, pp. 15-25.

Shi, Y-E. et al. 2012, 'Simulating urban development scenarios for Wuhan', China Planning Conference (IACP), 2012 6th International Association for 2012, Wuhan, China.

Shoko, M \& Smit, J 2013, 'Use of agent-based modelling to investigate the dynamics of slum growth', South African Journal of Geomatics, vol. 2, no. 1, pp. 54-67. 
South African Journal of Geomatics, Vol. 4, No. 1, February 2015

Sietchiping, R 2004, 'A geographic information systems and cellular automata-based model of informal settlement growth', Unpublished Doctoral dissertation, University of Melbourne, Melbourne, Australia.

StepSA, 2013a, Spatial Temporal Evidence for Planning, viewed 15 February 2013, http://stepsa.org/.

StepSA 2013b, 'Fact Sheet 5: Urban Spatial Simulation', StepSA, Pretoria, South Africa.

Teitz, B.M., Dietzel, C. \& Fulton, W. 2005. 'Urban development futures in the San Joaquin Valley', Public Policy Institute of California.

Tobler, WR 1970, 'A Computer Movie Simulating Urban Growth in the Detroit Region', Economic Geography, vol. 46, June, pp. 234-240.

Torrens, PM \& O'Sullivan, D 2001, 'Cellular Automata and Urban Simulation: Where Do We Go From Here?' Environment \& Planning B: Planning and Design, vol. 28, no. 2, pp. 163-168.

UNCHS (United Nations Centre for Human Settlements) 2012, State of the World Cities, 2012/2013: Prosperity of Cities, United Nations Human Settlements Programme (UN-HABITAT), Nairobi, Kenya.

Waddell, P 2002, 'UrbanSim: Modelling Urban Development for Land Use, Transportation and Environmental Planning', Journal of the American Planning Association, vol. 68, no. 3, pp. 297-314.

Waddell, P, Borning, A, Noth, M, Freier, N, Becke, M \& Ulfarsson, G 2003, 'Microsimulation of Urban Development and Location Choices: Design and Implementation of UrbanSim', Networks and Spatial Economics, vol. 3, pp. 43-67.

Waddell, P 2011, Dynamic microsimulation: UrbanSim Webinar 5 of an 8-part TMIP Webinar series on land use forecasting methods, viewed 18 September 2012, http://www.urbansim.org/Documentation/Classroom/WebHome.

Waldeck, L 2007, 'Progress report on establishing the Urban Dynamics Library', CSIR, Pretoria, South Africa.

Wang, J, Lu, H \& Peng, H 2008, 'System dynamics model of urban transportation system and its application', Journal of Transportation Systems Engineering and Information Technology, vol. 8, no.3, pp. 83-89.

Wegener, M 2004, 'Overview of Land-Use Transport Models', in D Hensher and K Button (eds.), Transport Geography and Spatial Systems. Handbook 5 of the Handbook in Transport. Pergamon/Elsevier Science, Kidlington, UK.

Wray, C \& van Olst, R 2012, 'Enabling g-government in the Gauteng City-Region', The African Journal of Information and Communication, vol. 12, pp. 65-83.

Young, G 2010, 'Socioeconomic analysis of informal settlement growth in Dar es Salaam: the concept for an agent-based model', Unpublished Masters' Thesis, University of Twente, Enschede, The Netherlands.

$\mathrm{Yu}, \mathrm{W}, \mathrm{Zang}, \mathrm{S}, \mathrm{Wu}, \mathrm{C}, \mathrm{Liu}, \mathrm{W} \& \mathrm{Na}, \mathrm{X}$ 2011, 'Analyzing and modelling land use land cover change (LUCC) in the Daqing City, China', Applied Geography, vol. 31, pp. 600-608.

Zeng, YN, Wu, GP, Zhan, FB \& Zhang, HH 2008, 'Modelling spatial land use pattern using auto-logistic regression', The International Archives of the Photogrammetry, Remote Sensing and Spatial Information Sciences, vol. XXXVII.I, pp. 115-118. 